\title{
Knowledge, Attitude and Practice of Infection Control Measures in Private Dental Clinics in Jeddah, Saudi Arabia
}

\author{
Ali AlAhdal ${ }^{1 *}$, Wejdan Aljehani ${ }^{2}$, Ghada Ali ${ }^{2}$ and Amr Bayoumi ${ }^{3}$ \\ ${ }^{1}$ Dentist, Infection Preventionist, Planning and Research Directorate, Makkah Health Affairs, MOH, Saudi Arabia \\ ${ }^{2}$ Dental intern, Faculty of Dentistry, King Abdulaziz University, Jeddah, Saudi Arabia \\ ${ }^{3}$ Professor of Oral and Maxillofacial Surgery, Faculty of Dentistry, King Abdulaziz University, Jeddah, Saudi Arabia
}

*Corresponding author: Ali AlAhdal, Dentist, Infection Preventionist, Planning and Research Directorate, Makkah Health Affairs, MOH, Saudi Arabia, Tel: +966567572600; E-mail: ali-alahdal10@hotmail.com

Received: 04 Jan, 2019 | Accepted: 31 Jan, 2019 | Published: 06 Feb, 2019

Citation: AlAhdal A, Aljehani W, Ali G, Bayoumi A (2019) Knowledge, Attitude and Practice of Infection Control Measures in Private Dental Clinics in Jeddah, Saudi Arabia. Int J Dent Oral Health 5(1): dx.doi.org/10.16966/2378-7090.286

Copyright: (C) 2019 AlAhdal A, et al. This is an open-access article distributed under the terms of the Creative Commons Attribution License, which permits unrestricted use, distribution, and reproduction in any medium, provided the original author and source are credited.

\begin{abstract}
Introduction: Dental health care providers (DHCPs) are exposed to many hazards during dental treatment including cross-infection of blood-borne pathogens. Various microorganisms can be easily transmitted in a dental clinic setup, such as HBV, HCV, HIV as well as other viruses and bacteria. This study aims to assess the level of knowledge, attitude and practice of infection control (IC) measures of the DHCPs in the private dental sector in Jeddah, Saudi Arabia.

Material and Method: This study was conducted between December 2017 and February 2018. A self-administered questionnaire was used which was consisted of four sections related to infection control guidelines covering their general background, infection control knowledge, attitude toward the infection control in the dental clinics and finally practicing infection control in their clinics.

Results: A total of 245 DHCPs ( 108 males $44.1 \%, 137$ females $55.9 \%$ ) in private clinics participated in the study. 115 had less than five years of experience $(46.9 \%) .7 .3 \%$ of them $(n=18)$ were not vaccinated against HBV. $26.9 \%$ of DHCPs $(n=66)$ did not realize that the risk of acquiring HBV infection is higher than HIV in dental practice whereas $55.5 \%$ dentists ( $n=136)$ were not aware of the management of needlestick and sharps injuries. $33.5 \%$ of participants $(n=82)$ think that wearing gloves replaces the need of hand wash. 3.3\% did not perform hand hygiene after contacting each patient and $46.5 \%$ did not know the correct duration of hand hygiene. Many dentists were not compliant with standard precautions of IC, e.g., the unsafe behavior of bending needles after use $(n=72 ; 29.4 \%)$, did not wear a gown ( $n=67 ; 27.3 \%)$ and did not wear masks during patient treatment $(n=14 ; 5.7 \%)$. Data analysis also revealed that knowledge and attitude scores were significantly higher among participants who have a postgraduate education than participants with a diploma or bachelor degrees. Nevertheless, the correct practice score was higher among diploma or bachelor degrees than participants with higher education.
\end{abstract}

Conclusion: IC knowledge and practice among DHCPs in private clinics in Jeddah needs improvement. Continued education and obligatory IC training programs are recommended to improve their practice and update their knowledge.

Keywords: Dental infection prevention; Infection control in dental clinics; Infection control knowledge; Infection control practice

\section{Introduction}

The oral cavity is a natural foundation for a large number of microorganisms [1]. Therefore, dental health care providers (DHCPs) are exposed to many hazards during dental treatment including crossinfection of blood-borne pathogens [2]. Cross-infection can be defined as the transmission of infectious agents between patients and staff within a clinical environment. Various microorganisms can be easily transmitted in a dental clinic setup, such as HBV, $\mathrm{HCV}, \mathrm{HIV}$ as well as other viruses and bacteria [3]. Several ways can carry these infections; either directly through contact with blood or blood-contaminated saliva, indirectly through contact with infected instruments or via airborne contaminants in either splatter or aerosol [4].
Majority of patients carrying infectious diseases may be unaware of their status or cannot be identified clinically [5]. Therefore, infection control guidelines must be implemented and followed to ensure a safe working environment and minimize the risk of cross-infection regardless of the patient's infection status alongside with vaccination against common infections, hand hygiene, personal barrier protection, instrument disinfection and sterilization protocols, as well as proper post-exposure management $[1,6]$.

Centers for Disease Control and Prevention (CDC), in collaboration with infection control experts from other federal agencies, academia, private and governmental professional organizations, published Guidelines for Infection Control in Dental Health-Care Settings-2003 [7]. 
DHCPs compliance with these guidelines has been previously studied in different parts of the world and it indicates the presence of gaps between dentists' knowledge. However, to the best of the researcher's knowledge, data regarding the private sector in Saudi Arabia are limited and practically lacking in Jeddah. This study aims to assess the level of knowledge, attitude and practice of infection control measures in the private dental sector in Jeddah, Saudi Arabia.

\section{Material and Methods}

This study was conducted between December 2017 and February 2018. Three hospitals and 46 private dental clinics were included from different districts in Jeddah, Saudi Arabia. A self-administered questionnaire-which was designed by the study investigators-was used for data collection. For validation process, a professional infection preventionest evaluated the structure of the questionnaire and the relevancy of the contents. After that, a pilot study has been completed upon 27 participants to check for the feasibility of the questionnaire by obtaining their feedback. The results revealed that it was convenient and viable and only minor changes have been made. A systematic random sampling method was used to select subjects. The first sample was chosen randomly by picking a number from a jar where each facility was given a number.

The questionnaire consisted of four sections. The first section covered the general background with five questions related to gender, level of education, specialty and years of experience. The second section covered infection control knowledge with six items assessing healthcare providers about sources of infection control knowledge, infectious diseases and transmission of infection, immunization and occupational accidents. The third section contained five questions about the attitudes related to infection control in the dental clinics. The fourth section was composed of 32 issues related to hand hygiene, personal protective equipment, disposal of sharp instruments and medical waste management, sterilization of dental instruments, the use of surface barriers, and impression disinfection. Ethical approval was obtained from the Research Ethics Committee of the Faculty of Dentistry (REC-FD), King Abdul Aziz University before starting the study.

\section{Results}

Data analysis was performed using Statistical Package for Social Sciences (IBM SPSS Statistics 24). A total of 245 DHCPs in private clinics participated in the study. Their demographic variables are shown in table 1.

Participants got their infection control information from different sources as shown in figure 1. The primary source of information was from undergraduate dental school courses (49\%) followed by seminar and conferences $(41 \%)$.

The second section of survey showed that $24 \%$ of the participants were not familiar with appropriate period to check for the postvaccination of HBV Antibody Blood Titer. Around 27\% of DHCPs $(n=66)$ did not realize that the risk of acquiring HBV infection is higher than HIV in dental practice whereas 56\% $(n=136)$ were not aware of the management of needle stick and sharps injury. Results of participants' responds to the knowledge section of the questionnaire are listed on table 2 .

The third section of the questionnaire (Table 3 ) revealed that most of the DHCPs understand that each patient should be treated as having an infectious disease. However, nearly $23 \%$ of them don't feel confident in providing treatment to an infectious patient. Unexpectedly, 10 DHCPs consider that disinfection of the dental clinics between patients is not required and about $34 \%(n=82)$ think that wearing gloves replace the need of hand wash. A considerable percentage (29.8 $\%)$ of the participants suppose that the needle recapping after local anesthesia is the responsibility of the assistant rather than the dentist.

Regarding the practice of IC, although a prominent percentage of participants had hepatitis B vaccination, approximately $7 \%$ of them $(n=18)$ were unvaccinated. In contrast, the results showed that 64.9 $\%(n=159)$ of the DHCPs were not vaccinated against influenza virus. Though the majority is conveniently performing hand hygiene before and after contact with each patient, around $30 \%$ mistakenly use hand rubbing with alcohol base antiseptics over hand washing with water and soap if their hands are visibly dirty or soiled with blood $\backslash$ body fluid. Moreover, $47 \%$ did not know the correct duration of hand hygiene. Many dentists were not compliant with the other standard precautions of IC, e.g. unsafe behavior of bending needles after use ( $n=72 ; 29.4 \%)$, not wearing a gown $(n=67 ; 27.3 \%)$ and not wearing masks during patient treatment $(\mathrm{n}=14 ; 5.7 \%)$. Additionally, the incorrect practice of opening drawers with contaminated gloved hands was reported by $26.1 \%$ of participants. Notably, only $50.6 \%$ of participants requested a monthly lab test to check the dental unit water and $38.4 \%$ checked their autoclave effectiveness using a biologic or spore test. Summary of the IC practiced by the DHCPs is demonstrated on table 4 .

Table 1: Participants demographic data.

\begin{tabular}{|c|c|c|c|}
\hline & & Count & $\%$ \\
\hline \multirow{2}{*}{ Gender } & Male & 108 & $44.10 \%$ \\
\hline & Female & 137 & $55.90 \%$ \\
\hline \multirow{3}{*}{ Education } & Diploma & 17 & $6.90 \%$ \\
\hline & Bachelor & 137 & $55.90 \%$ \\
\hline & Postgraduates & 91 & $37.10 \%$ \\
\hline \multirow{4}{*}{ Specialty } & Dental assistant or hygienist & 89 & $36.30 \%$ \\
\hline & General dentist & 67 & $27.30 \%$ \\
\hline & $\begin{array}{l}\text { Surgical dental specialty } \\
\text { (endodontic, periodontics, oral } \\
\text { surgery) }\end{array}$ & 36 & $14.70 \%$ \\
\hline & $\begin{array}{l}\text { Non-Surgical dental specialty } \\
\text { (restorative, pedodontic, } \\
\text { prosthodontic, oral medicine, } \\
\text { orthodontic) }\end{array}$ & 53 & $21.60 \%$ \\
\hline \multirow{3}{*}{ Experience } & $<5$ years & 115 & $46.90 \%$ \\
\hline & $5-10$ years & 67 & $27.30 \%$ \\
\hline & $>10$ years & 63 & $25.70 \%$ \\
\hline
\end{tabular}

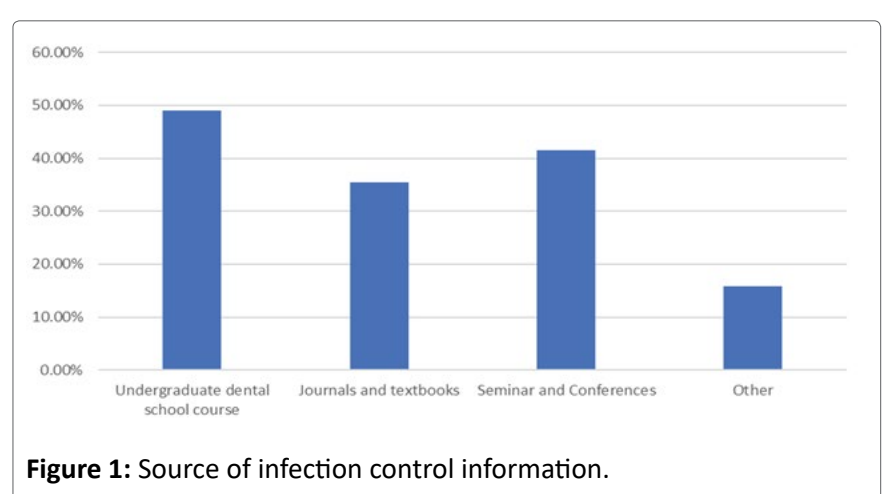

Figure 1: Source of infection control information. 
Table 2: Infection control knowledge.

\begin{tabular}{|c|c|c|c|}
\hline Question & & Count & $\%$ \\
\hline \multirow{2}{*}{$\begin{array}{l}\text { How often post-vaccination of HBV } \\
\text { antibody blood titer should be checked? }\end{array}$} & Wrong & 59 & $24.10 \%$ \\
\hline & Correct & 186 & $75.90 \%$ \\
\hline \multirow{2}{*}{$\begin{array}{l}\text { Which of the following (HBV, HCV, HIV) } \\
\text { has the highest risk of transmission in } \\
\text { dental practice? }\end{array}$} & Wrong & 66 & $26.90 \%$ \\
\hline & Correct & 179 & $73.10 \%$ \\
\hline \multirow{2}{*}{$\begin{array}{l}\text { What is the risk of HIV transmission } \\
\text { after a single contaminated needle stick } \\
\text { injury? }\end{array}$} & Wrong & 151 & $61.60 \%$ \\
\hline & Correct & 94 & $38.40 \%$ \\
\hline \multirow{2}{*}{$\begin{array}{l}\text { What is the risk of HBV transmission } \\
\text { after a single contaminated needle stick } \\
\text { injury? }\end{array}$} & Wrong & 133 & $54.30 \%$ \\
\hline & Correct & 112 & $45.70 \%$ \\
\hline \multirow{2}{*}{$\begin{array}{l}\text { What should you do immediately in } \\
\text { case of a needle stick injury? }\end{array}$} & Wrong & 136 & $55.50 \%$ \\
\hline & Correct & 109 & $44.50 \%$ \\
\hline
\end{tabular}

Table 3: Infection control attitude.

\begin{tabular}{|c|c|c|c|}
\hline Questions & & Count & $\%$ \\
\hline \multirow{2}{*}{$\begin{array}{l}\text { Do you think that every patient in the } \\
\text { dental clinic must be considered as } \\
\text { having an infectious disease? }\end{array}$} & Wrong & 26 & $10.60 \%$ \\
\hline & Correct & 219 & $89.40 \%$ \\
\hline \multirow{2}{*}{$\begin{array}{l}\text { Do you feel confident when treating } \\
\text { patients with infectious disease? }\end{array}$} & Wrong & 56 & $22.90 \%$ \\
\hline & Correct & 189 & $77.10 \%$ \\
\hline \multirow{2}{*}{$\begin{array}{l}\text { Do you think disinfection of the dental } \\
\text { unit and clinic is required after each } \\
\text { patient? }\end{array}$} & Wrong & 10 & $4.10 \%$ \\
\hline & Correct & 235 & $95.90 \%$ \\
\hline \multirow{2}{*}{$\begin{array}{l}\text { Do you think wearing gloves replace the } \\
\text { need of hand wash? }\end{array}$} & Wrong & 82 & $33.50 \%$ \\
\hline & Correct & 163 & $66.50 \%$ \\
\hline \multirow{2}{*}{$\begin{array}{l}\text { Who do you think should recap the } \\
\text { needle after injecting local anesthesia? }\end{array}$} & Wrong & 73 & $29.80 \%$ \\
\hline & Correct & 172 & $70.20 \%$ \\
\hline
\end{tabular}

Using t-test, as shown in table 5, male participants had higher knowledge and attitude scores than females. However, the practice score was not significantly different by gender.

Applying ANOVA with Tukey post hoc tests, the knowledge score was not significantly different by educational level. However, the attitude of post-graduate participants was significantly higher than bachelor participants $(\mathrm{p}<0.001)$ and diploma participants $(\mathrm{p}<0.001)$. In term of practice, the bachelor participants had significantly higher practice score than post-graduate participants $(\mathrm{p}=0.024)$.

Using the same tests, the knowledge and practice scores were not significantly different by years of experience. Only the attitude level of participants who have more than 10 years of experience was significantly higher than those with less than 5 years of experience $(\mathrm{p}=0.018)$.

Simple linear regression revealed a significant relationship between infection control knowledge score and correct practice $(\mathrm{p}<0.001$, $\mathrm{R}$-squared $=0.072$ ) as seen in figure 2 . However, there was no significant relationship between infection control attitude score and correct practice $(\mathrm{p}=0.257)$.

\section{Discussion}

This study aims to assess the knowledge, attitude, and practice of infection control in the private dental sector in Jeddah. Hand hygiene is considered one of the most effective ways to reduce the risk of crossinfection. Most of the participants in this study have correct knowledge about standard precautions of hand hygiene. However, a considerable percentage of them did not know the exact duration (46.5\%). Similar results were reported by other studies in Saudi Arabia. A survey by Mandourh [8] which was done in Makkah showed that (40.2\%) did not perform hand hygiene for an adequate duration. Another survey in Hail [9] revealed that only (73\%) denied that wearing gloves replace the need for hand washing which is consistent with the findings of the current study (66.5\%). On the other hand, a study in Lebanon [10] reported that $(90 \%)$ of dentists apply the correct measures of hand hygiene.

Most of the DHCPs in the present study adhere to infection control guidelines regarding the use of surface barriers to cover the dental unit contact surfaces and only (2.9\%) did not follow them. These findings varied from an earlier study that was done in Lebanon [10] where (55\%) did not use surface barriers for high contact surfaces.

Regarding personal protective equipment, only (24\%) in the present study did not wear eye protection and (5.7\%) did not wear a mask during patient treatment. However, a higher percentage have been reported in Lebanon (10) where more than half of participants (54.3\%) did not wear eye protection and $(10.9 \%)$ did not wear a mask when treating patients.

In this study, a significant percentage of participants have been vaccinated against HBV (90.6\%). This percentage is relatively higher than which was reported by Mandourh [8] where (85\%) were vaccinated. Other studies in Riyadh [11] and Hail [9] also reported a very close vaccination rate $(88 \%)$ of participants. These results show a satisfactory level of awareness among DHCPs in Saudi Arabia compared to that recorded by Alomari in North Jordan [5] which revealed only that (36\%) are vaccinated.

Majority of participants in the current study were not aware of the correct management of needle stick injury (55\%). Such a lower level of awareness of the control of the sharp injuries might jeopardize the safety of the DHCPs and put them at risk of acquiring blood-borne diseases.

DHCPs in Jeddah generally display good practices to standard infection control guidelines except for a few procedures which may be correlated to the fact that only (49\%) of participants received Continued Educational Courses in infection control. Unlike Makkah where $(71 \%)$ of them received courses.

Transmission of blood-borne pathogens in the dental settings is not common nowadays. Though, the consequences of such an event are not favorable as it influences the quality of life of both affected DHCPs and the patients. In the US, only three published investigation reports were found on the transmission of HBV and HCV in dental practice with seven total infected cases from 2003 to 2015 [12]. Even though the reports always failed to link faulty IC practices to the transmission events, Identification of errors in infection prevention practices happened during two of the investigations. Examples of these errors were recognized as using unsuccessfully sterilized hand pieces, hiring volunteers without proper training on the precautions of the transmission of the blood-borne pathogens and the use of a combination of unsafe injection practices. Such low incidents of cross-infection in the dental settings could be associated with the generalized application of the universal IC precautions since the HBV outbreak in 1978 then the same instructions were emphasized after the HIV outbreak in 1983. 
Table 4: Infection control practice.

\begin{tabular}{|c|c|c|c|}
\hline Questions & & Count & $\%$ \\
\hline \multirow{2}{*}{ Are you vaccinated against HBV? } & Wrong & 18 & $7.35 \%$ \\
\hline & Correct & 227 & $92.65 \%$ \\
\hline \multirow{2}{*}{ Are you vaccinated against influenza? } & Wrong & 159 & $64.90 \%$ \\
\hline & Correct & 86 & $35.10 \%$ \\
\hline \multirow{2}{*}{ Do you check the medical history of each new patient before treatment? } & Wrong & 11 & $4.50 \%$ \\
\hline & Correct & 234 & $95.50 \%$ \\
\hline \multirow{2}{*}{ Do you check the medical history of each previous patient for changes? } & Wrong & 44 & $18.00 \%$ \\
\hline & Correct & 201 & $82.00 \%$ \\
\hline \multirow{2}{*}{ Do you preform hand hygiene before contacting each patient? } & Wrong & 26 & $10.60 \%$ \\
\hline & Correct & 219 & $89.40 \%$ \\
\hline \multirow{2}{*}{ Do you preform hand hygiene after contacting each patient? } & Wrong & 8 & $3.30 \%$ \\
\hline & Correct & 237 & $96.70 \%$ \\
\hline \multirow{2}{*}{$\begin{array}{l}\text { How do you clean your hands when they are visibly dirty or soiled with blood \body } \\
\text { fluid? }\end{array}$} & Wrong & 74 & $30.20 \%$ \\
\hline & Correct & 171 & $69.80 \%$ \\
\hline \multirow{2}{*}{ For how long do you rub your hands with an alcohol-based antiseptic solution? } & Wrong & 114 & $46.50 \%$ \\
\hline & Correct & 131 & $53.50 \%$ \\
\hline \multirow{2}{*}{ For how long do you wash your hands with soap and water? } & Wrong & 114 & $46.50 \%$ \\
\hline & Correct & 131 & $53.50 \%$ \\
\hline \multirow{2}{*}{ Do you let your hands dry completely before putting on gloves? } & Wrong & 8 & $3.30 \%$ \\
\hline & Correct & 237 & $96.70 \%$ \\
\hline \multirow{2}{*}{ In what order do you put on your personal protective equipment (PPE)? } & Wrong & 54 & $22.00 \%$ \\
\hline & Correct & 191 & $78.00 \%$ \\
\hline \multirow{2}{*}{ In what order do you remove your personal protective equipment (PPE)? } & Wrong & 70 & $28.60 \%$ \\
\hline & Correct & 175 & $71.40 \%$ \\
\hline \multirow{2}{*}{ Do you always wear gloves while treating a patient? } & Wrong & 2 & $0.80 \%$ \\
\hline & Correct & 243 & $99.20 \%$ \\
\hline \multirow{2}{*}{ Do you change your gloves between patients, or when they are being torn? } & Wrong & 3 & $1.20 \%$ \\
\hline & Correct & 242 & $98.80 \%$ \\
\hline \multirow{2}{*}{ Do you always wear a face mask while treating a patient? } & Wrong & 14 & $5.70 \%$ \\
\hline & Correct & 231 & $94.30 \%$ \\
\hline \multirow{2}{*}{ Do you change your face mask between patients, or when it is wet? } & Wrong & 24 & $9.80 \%$ \\
\hline & Correct & 221 & $90.20 \%$ \\
\hline \multirow{2}{*}{ Do you always wear a disposable gown while treating a patient? } & Wrong & 67 & $27.30 \%$ \\
\hline & Correct & 178 & $72.70 \%$ \\
\hline \multirow{2}{*}{ Do you change your gown between patients? } & Wrong & 95 & $38.80 \%$ \\
\hline & Correct & 150 & $61.20 \%$ \\
\hline \multirow{2}{*}{$\begin{array}{l}\text { Do you always wear a face shield leye protection if a high speed hand piece, straight } \\
\text { hand piece or ultrasonic scaler is going to be used? }\end{array}$} & Wrong & 59 & $24.10 \%$ \\
\hline & Correct & 186 & $75.90 \%$ \\
\hline \multirow{2}{*}{ Do you disinfect your protective eyewear after each patient? } & Wrong & 39 & $15.90 \%$ \\
\hline & Correct & 206 & $84.10 \%$ \\
\hline \multirow{2}{*}{ Do you use protective barriers to cover the dental unit contact surfaces? } & Wrong & 7 & $2.90 \%$ \\
\hline & Correct & 238 & $97.10 \%$ \\
\hline \multirow{2}{*}{ Do you clean and rub the dental chair before starting your daily work? } & Wrong & 3 & $1.20 \%$ \\
\hline & Correct & 242 & $98.80 \%$ \\
\hline \multirow{2}{*}{ Do you clean and disinfect surfaces between appointments? } & Wrong & 12 & $4.90 \%$ \\
\hline & Correct & 233 & $95.10 \%$ \\
\hline Rover keen cterila inctrumentc in noushec untilucage? & Wrong & 4 & $1.60 \%$ \\
\hline Do you keep sterlle instruments in poucnes unti usage? & Correct & 241 & $98.40 \%$ \\
\hline
\end{tabular}




\begin{tabular}{|c|c|c|c|}
\hline \multirow{2}{*}{ Do you use Class B autoclave for instruments sterilization? } & Wrong & 128 & $52.20 \%$ \\
\hline & Correct & 117 & $47.80 \%$ \\
\hline \multirow{2}{*}{ Do you check your autoclave using a biologic or spore test at least monthly? } & Wrong & 151 & $61.60 \%$ \\
\hline & Correct & 94 & $38.40 \%$ \\
\hline \multirow{2}{*}{ Do you disinfect impressions before sending to the lab? } & Wrong & 12 & $4.90 \%$ \\
\hline & Correct & 233 & $95.10 \%$ \\
\hline \multirow{2}{*}{ Do you open the drawers while wearing gloves during treatment sessions? } & Wrong & 64 & $26.10 \%$ \\
\hline & Correct & 181 & $73.90 \%$ \\
\hline \multirow{2}{*}{ Do you bend the needle after using it? } & Wrong & 72 & $29.40 \%$ \\
\hline & Correct & 173 & $70.60 \%$ \\
\hline \multirow{2}{*}{ Do you recap the needle "one-hand scoop technique" by yourself after using it? } & Wrong & 25 & $10.20 \%$ \\
\hline & Correct & 220 & $89.80 \%$ \\
\hline \multirow{2}{*}{ Do you dispose the sharp waste in the sharps container? } & Wrong & 2 & $0.80 \%$ \\
\hline & Correct & 243 & $99.20 \%$ \\
\hline \multirow{2}{*}{ Do you separate blood soaked waste from ordinary waste? } & Wrong & 31 & $12.70 \%$ \\
\hline & Correct & 214 & $87.30 \%$ \\
\hline \multirow{2}{*}{ Do you monthly request a lab test to check your dental unit water? } & Wrong & 121 & $49.40 \%$ \\
\hline & Correct & 124 & $50.60 \%$ \\
\hline
\end{tabular}

Table 5: The difference in knowledge, attitude and practice score by gender, education level and years of experience using t-test and ANOVA.

\begin{tabular}{|c|c|c|c|c|c|c|c|}
\hline & & Knowledge mean (SD) & p-value & Attitude mean (SD) & p-value & Practice mean (SD) & p-value \\
\hline \multirow{2}{*}{ Gender } & Male & $2.57(1.02)$ & 0.001 & $4.3(0.79)$ & $<0.001$ & $25.14(3.52)$ & 0.291 \\
\hline & Female & $2.12(1.03)$ & & $3.75(0.96)$ & & $25.59(3.05)$ & \\
\hline \multirow{3}{*}{ Education } & Diploma & $2.0(1.0)$ & 0.059 & $3.41(0.87)$ & $<0.001$ & $26.24(2.88)$ & 0.018 \\
\hline & Bachelor & $2.21(1.03)$ & & $3.8(0.95)$ & & 25.79 (3.19) & \\
\hline & Postgraduates & $2.54(1.05)$ & & $4.4(0.74)$ & & $24.64(3.35)$ & \\
\hline \multirow{3}{*}{ Experience } & $<5$ years & $2.27(1.06)$ & 0.617 & $3.86(0.94)$ & 0.025 & $25.45(3.23)$ & 0.766 \\
\hline & 5-10 years & $2.3(0.97)$ & & $3.97(0.85)$ & & $25.15(3.54)$ & \\
\hline & $>10$ years & $2.43(1.1)$ & & $4.25(0.93)$ & & $25.54(3.06)$ & \\
\hline
\end{tabular}

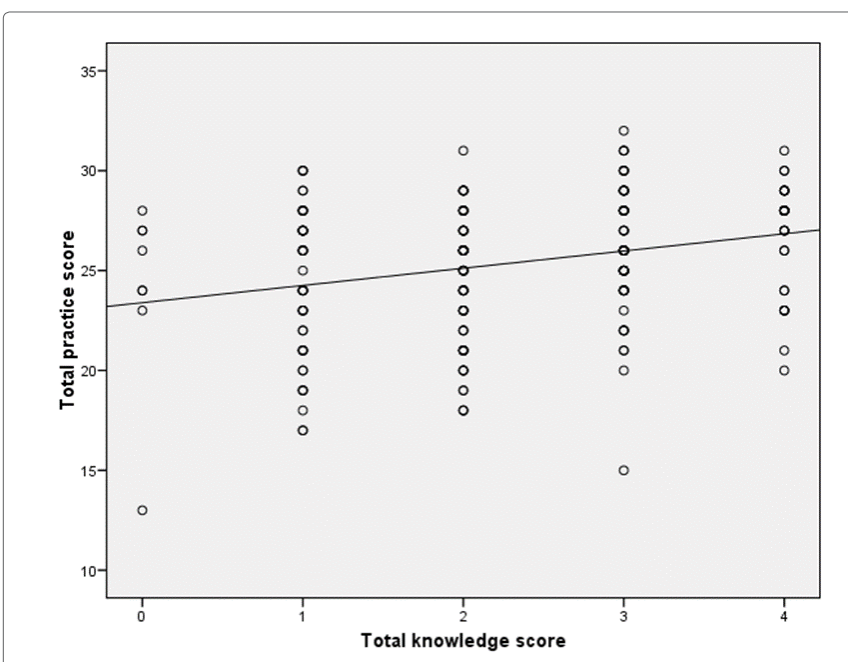

Figure 2: The relation between infection control knowledge score and correct practice score.
South worth published a systematic review article in 2014 that aimed to view the reported outbreaks and incidents associated with failures in the decontamination process of surgical instruments in healthcare services. The results of this review were that many incidents involved the disinfection, rather than sterilization, of surgical instruments ( $43 \%$ of articles). Armamentarium used in ocular surgery was often reported to be associated with decontamination failures ( $29 \%$ of articles). Of the few articles describing potential or confirmed pathogenic transmission, Pseudomonas aeruginosa and Mycobacterium $s p p$. were most represented. One event of possible variant CreutzfeldtJakob disease transmission was also identified. Relatively, there is a low risk of cross-infection through reusable surgical instruments when cleaning/sterilization procedures are adhered to. The study concluded that infection prevention and control teams should recognize this, and healthcare workers should be encouraged to report any incidents comprehensively, thus enabling future analysis, assessment of current situations, and the learning of lessons from previous errors. This study recommended that a multidisciplinary quality control program should be applied to prevent contamination of the patients due to 
failure in the sterilization process and more educational program shall be implemented [13]. These conclusion and recommendations are not far away from dental care services. Dental burs, bone cutters, extraction forceps and many dental instruments are used surgically penetrating the sterile tissues of the body and increase the risk of cross infection if IC measures are not strictly followed. There is also a risk for transmission of some respiratory diseases including Legionnaires' disease in the dental office due to contamination of the water line system [14]. Testing the dental units' water is one of the neglected IC measures for almost half of the participants in our study.

Su, Deng and Sun published a study in 2012 that aimed to survey changes in practices of infection control (IC) procedures by dentists in Beijing between 2000 and 2010. The percentages of dentists who had received training in IC were $62.96 \%$ (2000) and increased to $76.21 \%$ (2010). Improvements in practices in 2010 over those in 2000 included increasing in: the percentage of vaccination for hepatitis B virus, the routine use of gloves, the use of face shields or eyewear as protection against splatter during dental treatment, the utilization of protective gowns increased, the application of high-volume suction, routine changing of gloves between patients, pressured steam sterilization of dental hand pieces between, and the flushing of dental unit waterlines after each treatment. They concluded that although compliance with recommended IC practices by dentists in Beijing improved between 2000 and 2010, not all dentists are adequately familiar with IC procedures. The study recommendation was that education in IC in dental schools, continuing training in hospitals and mandatory regulations are needed to improve IC practices in dental health care settings [15]. The same conclusion was also reported and emphasized by Tamil selvi and associates to be effective through a quality improvement project [16].

\section{Conclusion}

Infection control knowledge and practice among DHCPs in private clinics in Jeddah needs improvement. Therefore, we highly recommend that all dentists in private clinics receive continued education and obligatory IC training programs to improve their practice and update their knowledge. Also, hepatitis B vaccination should be included as a mandatory prerequisite for the completion of registration in the Saudi Commission for Health Specialties, with periodic evaluation of antibody level to reduce the possibility of cross-infection within the community.

\section{References}

1. Laheij A, Kistler J, Belibasakis G, Välimaa H, De Soet J (2012) Healthcare-associated viral and bacterial infections in dentistry. J Oral Microbiol 4: 17659.

2. Gerberding JL (1994) Incidence and prevalence of human immunodeficiency virus, hepatitis B virus, hepatitis C virus, and cytomegalovirus among health care personnel at risk for blood exposure: final report from a longitudinal study. J Infect Dis 170: 1410-1417.

3. Al-Maweri SA, Tarakji B, Shugaa-Addin B, Al-Shamiri HM, Alaizari NA, et al. (2015) Infection control: Knowledge and compliance among Saudi undergraduate dental students. GMS Hyg Infect Control.

4. Taiwo JO, Aderinokun GA (2002) Assessing cross infection prevention measures at the Dental Clinic, University College Hospital, Ibadan. Afr J Med Med Sci 31: 213-217.

5. Al-Omari MA, Al-Dwairi ZN (2005) Compliance with infection control programs in private dental clinics in Jordan. J Dent Educ 69: 693-698.

6. Al-Anesi MS, Alhajj MN, Al-Basmi AA (2017) Compliance of Dental Students toward Infection Control in Dental Teaching Hospital at Thamar University-Yemen. Braz Dent Sci 20: 40-48.

7. Cleveland JL, Bonito AJ, Corley TJ, Foster M, Barker L, et al. (2012) Advancing infection control in dental care settings: factors associated with dentists' implementation of guidelines from the Centers for Disease Control and Prevention. J Am Dent Assoc 143: 1127-1138.

8. Mandourh MS, Alhomaidhi NR, Fatani NH, Alsharif AS, Ujaimi GK, et al. (2017) Awareness and implementation of infection control measures in private dental clinics, Holy Makkah, Saudi Arabia. Int J Infect Control 13: 1-14.

9. Haridi HK, Al-Ammar AS, Al-Mansour MI (2016) Compliance with infection control standard precautions guidelines: a survey among dental healthcare workers in Hail Region, Saudi Arabia. J Infect Prev 17: 268-276.

10. Dagher J, Sfeir C, Abdallah A, Majzoub Z (2017) Infection Control Measures in Private Dental Clinics in Lebanon. Int J Dent.

11. Al-Rabeah A, Moamed AG (2002) Infection control in the private dental sector in Riyadh. Ann Saudi Med 22: 13-17.

12. Cleveland JL, Gray SK, Harte JA, Robison VA, Moorman AC, et al. (2016) Transmission of blood-borne pathogens in US dental health care settings: 2016 update. J Am Dent Assoc 147: 729-738.

13. Southworth PM (2014) Infections and exposures: reported incidents associated with unsuccessful decontamination of reusable surgical instruments. J Hosp Infect 88: 127-131.

14. Volgenant CMC, de Soet JJ (2018) Cross-transmission in the Dental Office: Does This Make You III? Curr Oral Health Rep 5: 221-228.

15. Su J, Deng XH, Sun Z (2012) A 10-year survey of compliance with recommended procedures for infection control by dentists in Beijing. Int Dent J 62: 148-153.

16. Tamilselvi M, Srinivas A (2016) Clinical Quality Strategy Facilitates Effective Quality System Implementation For Prevention of Healthcare Associated Infections. Management in Health 20. 